\title{
CONGENITAL DEFECTS AMONG CHILDREN BORN TO WOMEN UNDER SUPERVISION OR TREATMENT FOR PULMONARY TUBERCULOSIS
}

\author{
BY \\ C. R. LOWE \\ Department of Social and Occupational Medicine, Welsh National School of Medicine, Cardiff
}

The results of a survey published by McDonald (1961) suggest that children born to women with pulmonary tuberculosis may show an excess of serious congenital malformations. Among a random sample of 3,295 pregnant women who were interviewed at their first antenatal visit and followed up to ascertain the outcome of their pregnancies, 61 gave a history of pulmonary tuberculosis and four of the children born to them were subsequently found to have major congenital defects (two were anencephalic, one had absent kidneys, and one a cardiac defect).

Although the thalidomide disaster has underlined the need for the utmost caution when prescribing drugs for women who are or may be in the early months of pregnancy, no attempt appears to have been made to confirm or refute this observation, with its implication that one of the drugs currently used in the treatment of tuberculosis may be teratogenic. There is an additional reason for concern in that laboratory experiments suggest that streptomycin is teratogenic for rats (Filippi and Mela, 1958).

The outcome of 253 pregnancies in women known to have been under supervision or treatment for pulmonary tuberculosis during pregnancy is reported below.

\section{MethoD}

In June, 1962, the medical records of all women of reproductive age on the active register of the Cardiff Chest Clinic were carefully scrutinized. It was found that 206 women were reported to have had at least one pregnancy while under supervision or treatment for pulmonary tuberculosis during the preceding 5 years. One of these women had been pregnant four times, three three times, 38 twice, and the remaining 164 once only, so in all there were 253 related pregnancies, and since twelve of the pregnancies had ended before the 28 th week there were 241 confinements. All these confinements were traced in the local authority birth register; 198 had taken place in hospital (six of which had resulted in twin deliveries), forty at home, and three in private nursing homes.

An intensive search was then made for evidence of congenital defect in the 247 infants (twelve of them twins). To this end the obstetric records of all 198 hospital confinements were traced and examined, 42 of the 43 women who had had domiciliary or nursing home confinements were visited and interviewed, and the child examined (the woman who was not interviewed had left the district), local authority records of infant deaths over the related period were inspected (five of the infants had died during their first year), and local hospital records were searched for evidence of an outpatient attendance or an admission relating to any of the children.

Finally, when the search for congenital defects had been completed, details of any drug treatment for tuberculosis given to the women during the first 4 months of their pregnancies were extracted from the chest clinic records.

Since the purpose of the investigation was to test the hypothesis that one or more of the drugs currently used for the treatment of tuberculosis is teratogenic, no outside control group was used, the intention being to compare the incidence of congenital defects in children born to women under drug treatment during the early months of pregnancy with that in children born to women under supervision only.

\section{RESULTS}

\section{Foetal Loss and Infant Death}

It is notoriously difficult to arrive at a reliable estimate of foetal loss during the early months of pregnancy and figures ranging from 7 to 20 per cent. or higher can be quoted from the extensive literature on the subject. In the present series of 253 pregnancies, there were two ectopic pregnancies and ten abortions, one of which was induced for medical 
reasons. This represents an early foetal loss of about 5 per cent., which is unusually low.

An incomplete reporting of abortions in the medical records of a chest clinic was perhaps to be expected, but there is no obvious reason why pregnancies which resulted in stillbirth or infant death should have been under-reported, and both stillbirth rate and infant mortality were also low. Among the 247 births there were four stillborn infants, a stillbirth rate of about 16 per 1,000 total births, and five of the 243 live born infants died before their first birthday, an infant mortality of about 20 per 1,000 live births. The corresponding stillbirth rate for the City of Cardiff, where all the mothers were domiciled, was 22 and the corresponding infant mortality rate was 26.

Only one of the stillbirths was associated with obvious malformation (anencephaly). Of the remaining three, one was extremely premature and death was attributed to abruptio placentae, one was a fullterm infant of normal size with internal organs in an advanced state of post mortem change, and one was macerated but with no evidence of malformation.

Three of the infant deaths were attributed to gross congenital defects (one to myelomeningocele with spina bifida and talipes, one to ectopia vesica, and one to fibrocystic disease). One of the other two deaths was attributed to prematurity (with no evidence of malformation) and one to pneumonia.

From the above there is nothing to suggest that women with tuberculosis run an increased risk of abortion or stillbirth in pregnancy or of infant death after delivery. Before the introduction of effective therapy 16 years ago, stillbirth, maternal death, and infant death were of course all more common among women with active disease.

\section{INCIDENCE OF CONGENITAL DefeCtS}

Although at the time of their pregnancy all women included in the survey were on the city tuberculosis register, by no means all were under drug treatment. In fact only 31 per cent. (74) of the 241 pregnancies which resulted in live or stillborn infants were associated with drug treatment for tuberculosis at any time during the first 4 months of gestation (Table I). The treatment given consisted of various combinations of proprietary preparations of isoniazid, $p$ aminosalicylic acid, and streptomycin. The first two were the most commonly used drugs and both were administered during the early months of 68 pregnancies, although not in every case together. Streptomycin was much less popular, being administered in twelve pregnancies only, in six cases with isoniazid, in three with p-aminosalicylic acid, and in three with both those drugs.
TABLE I

DRUGS ADMINISTERED DURING THE FIRST 4 MONTHS OF PREGNANCY TO WOMEN UNDER SUPERVISION OR TREATMENT FOR PULMONARY TUBERCULOSIS

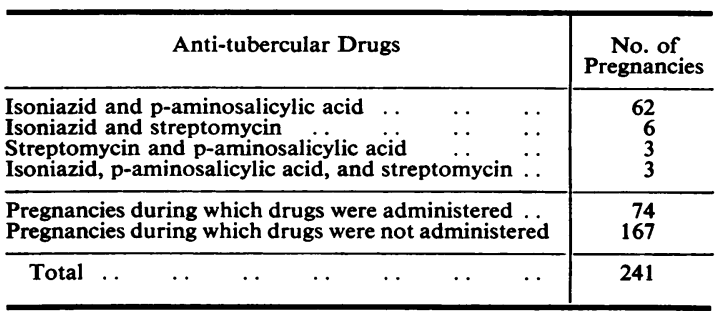

Table II (overleaf) lists the congenital defects discovered among the 247 infants of the 241 pregnancies in Table I. Of the 74 infants who were subjected to the influence of drugs in early foetal life, two $(2 \cdot 8$ per cent.) presented defects (Case 1, a female infant with myelomeningocele and other defects who died at 9 weeks, and Case 7, a male infant with hypospadias). Of the 173 infants who were not subjected to the influence of drugs, seven ( $4 \cdot 1$ per cent.) were found to have defects. There is little here to support the contention that congenital defects are commoner among infants born to women under active treatment for pulmonary tuberculosis and nothing to suggest that any of the commonly used drugs is teratogenic. This last conclusion is strengthened by the observation that the infant with gross, multiple malformations associated with p-aminosalicylic acid and isoniazid treatment (Case 1) was born to a woman who had two other pregnancies which are included in the present series: both produced normal infants, and one was also associated with p-aminosalicylic acid and isoniazid therapy in the early months.

\section{Discussion}

The data presented above provide no support for the hypothesis that one of the drugs commonly used in the treatment of pulmonary tuberculosis is teratogenic. They also suggest that the significance of the association between a history of tuberculosis in the mother and major congenital defect in the child found by McDonald (1961) in her prospective study of 3,278 pregnancies should be interpreted with caution. As she rightly pointed out, the likelihood of finding by chance a "statistically significant" association between some factor in the maternal history and a congenital defect is greatly increased when many different maternal factors are examined in relation to many different defects. 
TABLE II

CONGENITAL DEFECTS OBSERVED AMONG INFANTS BORN TO WOMEN UNDER SUPERVISION OR TREATMENT FOR PULMONARY TUBERCULOSIS

\begin{tabular}{|c|c|c|c|c|c|c|c|c|c|c|c|c|}
\hline \multirow{2}{*}{$\begin{array}{l}\text { Case } \\
\text { No. }\end{array}$} & \multirow{2}{*}{\multicolumn{7}{|c|}{ Defect }} & \multicolumn{2}{|c|}{$\begin{array}{l}\text { Drugs Adminis- } \\
\text { tered during } \\
\text { First } 4 \text { Months }\end{array}$} & \multicolumn{3}{|c|}{ Details } \\
\hline & & & & & & & & No & Yes & Sex & Drugs & Outcome \\
\hline 1 & Myelomeningocele, & spina & bifid & nd & pes & $\cdots$ & $\cdots$ & & 1 & $\mathbf{F}$ & PAS and INAH & Died at 9 wks \\
\hline 2 & Anencephaly .. & $\cdots$ & $\cdots$ & $\cdots$ & $\cdots$ & $\cdots$ & $\cdots$ & 1 & & $\mathbf{F}$ & & Stillborn \\
\hline 3 & Encephalocele & $\cdots$ & $\cdots$ & $\cdots$ & $\cdots$ & $\cdots$ & $\cdots$ & 1 & & $\mathbf{F}$ & & $\begin{array}{l}\text { Minor degree of } \\
\text { malformation only }\end{array}$ \\
\hline 4 & Ectopia vesica & $\cdots$ & $\cdots$ & $\cdots$ & $\cdots$ & $\cdots$ & $\cdots$ & 1 & & $\mathbf{F}$ & & Died at 3 wks \\
\hline 5 & Fibrocystic disease & $\cdots$ & $\cdots$ & $\cdots$ & $\cdots$ & $\cdots$ & $\cdots$ & 1 & & $\mathbf{F}$ & & Died at 12 wks \\
\hline 6 & Imperforate anus & $\cdots$ & $\cdots$ & $\cdots$ & $\cdots$ & $\cdots$ & $\cdots$ & 1 & & $\mathbf{M}$ & & Like-sexed twin \\
\hline 7 & Hypospadias & . & . & . & . & . & $\cdots$ & & 1 & $\mathbf{M}$ & PAS and INAH & \\
\hline 8 & Ventricular septal d & efect & $\cdots$ & $\cdots$ & $\cdots$ & $\cdots$ & $\cdots$ & 1 & & $\mathbf{F}$ & & Non-cyanotic \\
\hline 9 & Calcaneo valgus & $\cdots$ & $\cdots$ & $\cdots$ & $\cdots$ & $\cdots$ & $\cdots$ & 1 & & $\mathbf{F}$ & & $\begin{array}{l}\text { Suspected cretin } \\
\text { with pyloric } \\
\text { stenosis }\end{array}$ \\
\hline \multicolumn{2}{|c|}{ Total with Defects } & $\cdots$ & $\cdots$ & $\cdots$ & $\cdots$ & $\cdots$ & . & 7 & 2 & \multicolumn{3}{|c|}{9} \\
\hline \multicolumn{8}{|c|}{ Total without Defects } & 166 & 72 & \multicolumn{3}{|c|}{238} \\
\hline Grand Total & .. & . & . & . & $\cdots$ & . & . & 173 & 74 & \multicolumn{3}{|c|}{247} \\
\hline
\end{tabular}

In conclusion it should be mentioned that, in McDonald's series, two of the 61 infants born to women with a history of tuberculosis subsequently developed pyloric stenosis. The incidence of infantile pyloric stenosis in this country is probably about four per 1,000 live births (MacMahon, Record, and McKeown, 1951). Three of the 241 live-born infants in the Cardiff series developed the condition-an incidence of about 12 per 1,000 . However, it is difficult to imagine how maternal tuberculosis could increase the likelihood of an infant developing pyloric stenosis and the raised incidence is probably of no significance.

\section{SUMmaRY}

McDonald (1961) suggested that infants born to women with a history of tuberculosis show an excess of serious congenital defects. A study of the outcome of 253 pregnancies in women known to have been on the active register of the Cardiff Chest Clinic has failed to substantiate this.
During the first months of 74 of the pregnancies, various combinations of isoniazid, $p$-aminosalicylic 0 acid, and streptomycin had been administered. There? was nothing to suggest that any of the drugs was teratogenic.

The data indicate that women with respiratory tuberculosis no longer run an increased risk of stillbirth in pregnancy or of infant death after delivery.

I am grateful to Dr. S. H. Graham for permission to use the medical records at the Cardiff Chest Clinic and to Dr. R. L. H. Jones for collecting the data. The investigation was made possible by a grant from the Board of Governors of the United Cardiff Hospitals.

\section{REFERENCES}

Filippi, B., and Mela, V. (1958). Arch. franc. Pediat., 15, 565.

McDonald, A. D. (1961). Brit. J. prev. soc. Med., 15, 154. MacMahon, B., Record, R. G., and McKeown, T. (1951). Brit.J. soc. Med., 5, 185. 